JST 8 (1) (2019)
JURNAL SENI TARI
Thtp://journal.unnes.ac.id/sju/index.php/jst

\title{
Interaksi Simbolik pada Pertunjukan Sintren Desa Luwijawa Kecamatan Jatinegara Kabupaten Tegal
}

\author{
Ajeng Aulia Azzahro', R. Indriyanto \\ Jurusan Pendidikan Seni Drama Tari dan Musik, Fakultas Bahasa dan Seni, \\ Universitas Negeri Semarang, Indonesia
}

\section{Info Artikel}

Sejarah Artikel

Diterima : 20 Mei 2019

Disetujui : 24 Juni 2019

Dipublikasikan : 23 Juli

2019

\section{Keywords:}

Interaction; symbol; Sintren

\begin{abstract}
Abstrak
Tujuan penelitian ini untuk mengetahui bentuk pertunjukan Kesenian Sintren Desa Luwijawa dan memahami proses interaksi simbolik yang terjadi dalam pertunjukan Kesenian Sintren Desa Luwijawa. Penelitian ini bersifat kualitatif dengan menggunakan pendekatan etik dan emik. Data diperoleh melalui metode observasi, wawancara, dan dokumentasi. Teknik pengujian keabsahan data menggunakan teknik triangulasi. Teknik analisis data menggunakan teori Adshead. Hasil dari penelitian yaitu: 1) bentuk Pertunjukan meliputi elemen-elemen pertunjukan yaitu tema, pelaku pertunjukan, busana/kostum , make up/rias, iringan, properti, gerak, tempat pertunjukan, tata cahaya dan suara; 2) proses interaksi simbolik yang terjadi antara pemain dengan pemain, pemain dengan penonton, pemain dengan pemusik, pemusik dengan pemusik, penonton dengan penonton. Berdasarkan dari hasil penelitian Kesenian Sintren Desa Luwijawa, peneliti memberikan saran kepada anggota kelompok Kesenian Sintren agar pertunjukan Kesenian Sintren lebih variatif dan lebih menarik. Perhatikan proses regenerasi para pelaku pertunjukan Kesenian Sintren.
\end{abstract}

\section{Abstract}

The purposes of this study were to know the form of Sintren Art performance in Luwijawa Village and to understand the symbolic interaction process that occurs in the Sintren Art performance in Luwijawa Village. This was qualitative research by using ethics and emic descriptive approaches. The data was obtined through observation, interview, and documentation techniques. Triangulation technique was used to test the validity of data. Adshead's theory was used as data analysis technique. The research results were: 1) the form of the performance included the elements of the performance, namely the theme, performer, costume, makeup, accompaniment, property, motion, venue, lighting and sound; 2) the process of symbolic interaction occured between players and players, players and spectators, players and musicians, musicians and musicians, spectators and spectators. Based on the results of the Sintren Art Village study in Luwijawa, researcher gave suggestions to the Sintren Arts group members to give more varied and more interesting. In addition, pay attention to the regeneration process of the performers of Sintren.

(C) 2019 Universitas Negeri Semarang 


\section{PENDAHULUAN}

Di wilayah pesisir Utara Jawa Tengah, berkembang satu kesenian kerakyaan yang sudah ada sejak dulu yaitu Kesenian Sintren. Kesenian Sintren merupakan kesenian kerakyatan yang dimainkan secara berkelompok dengan tema legenda. Kesenian Sintren hadir dan berkembang hampir di seluruh daerah pantai Utara atau Pantura seperti Kendal, Batang, Pekalongan, Pemalang, Tegal, Brebes, dan Cirebon. Dari beberapa daerah yang memiliki Kesenian Sintren, tentu setiap daerah mempunyai bentuk pertunjukan yang berbeda, namun dasarnya masih sama. Semua Kesenian Sintren memiliki ciri khas yaitu penari Sintren akan dikurung dan dirasuki roh kemudian ketika kurungan dibuka Penari Sintren menari dengan tidak sadarkan diri.

Kesenian Sintren yang ada di

Desa Luwijawa Kecamatan Jatinegara Kabupaten Tegal memiliki bentuk pertunjukan dan beberapa ritual yang dilakukan sebelum memulai pertunjukan. Mbah Katri, wanita berusia lebih dari setengah abad berasal dari Desa Luwijawa menjadi penggerak diadakannya kembali pertunjukan Kesenian Sintren yang pernah vakum. Mbah Katri mengajak beberapa warga untuk kembali menghidupkan Kesenian Sintren. Awalnya pertunjukan Sintren diadakan semata hanya sebagai hiburan warga desa. Sebelum melakukan pertunjukan, Mbah Katri ditemani beberapa warga melakukan ritual-ritual khusus demi terciptanya pertunjukan. Kesenian Sintren sangat menarik untuk diteliti karena kesenian tersebut merupakan kesenian Sintren satu-satunya yang masih sering dipertunjukan dibanding Kesenian Sintren dari daerah lain di Kabupaten Tegal.

Simbol-simbol yang terdapat dalam pertunjukan Sintren dibagi menjadi dua, simbol verbal dan non verbal. Adanya simbol verbal terdapat dalam percakapan yang dilakukan oleh semua anggota dan pelaku pertunjukan, serta simbol non verbal yang yang terjadi di sela-sela komunikasi atau percakapan pelaku pertunjukan. Interaksi simbolik berupa verbal dan non verbal tersebut yang menambah ketertarikan peneliti untuk lebih mencari dan mengetahui semua keunikan Kesenian Sintren Desa Luwijawa Kecamatan Jatinegara Kabupaten Tegal.

Semua hal mengenai penari Sintren, penari Badut, dan mblandang yang juga menarik untuk diteliti. Faktor lain yang menjadikan peneliti tertarik meneliti Kesenian Sintren adalah banyaknya warga yang berantusias hadir menyaksikan pertunjukan sebagai tanda bahwa warga penasaran dan ingin tahu terhadap Kesenian Sintren. Faktor terpenting karena adanya proses interaksi antar penari Sintren dengan penonton, penari Sintren dengan pemain Badut, penari Sintren dengan mblandang, penonton dengan penonton yang terjadi sangat menarik untuk dikaji lebih dalam.

Masalah tentang interaksi simbolik pada Kesenian Sintren dikaji dengan teori Blummer (Hadi, 2015:43-46) yang apabila disimpulkan yaitu interaksi simbolik dijembatani dan dilihat melalui tiga proses yaitu: 1) pemikiran, merupakan sebuah proses berpikir dengan diri sendiri dimana pikiran akan mengolah informasi dan simbol yang diterima; 2) bahasa, dari bahasa memperoleh makna serta bahasa dapat dilakukan dengan verbal maupun non verbal; 3) pemaknaan, pada hakekanya bersumber dari interaksi atau simbol yang diterima dan dimknai oleh diri sendiri.

Interaksi merupakan proses yang erat kaitannya dengan komunikasi. karena berkomunikasi dengan berinteraksi dapat memudahkan seseorang untuk lebih menangkap makna yang disampaikan. Melalui berinteraksi, hubungan memberi dan menerima informasi antar sesama menjadi lebih mudah. Setiap hari manusia berkomunikasi dengan sesamanya, dan dapat dicermati komunikasi yang dilakukan selalu mengggunakan proses interaksi seperti gerak anggota tubuhnya, ekpresi wajah, dan hal lain yang memiliki simbol dan makna dalam proses komunikasinya. Proses komunikasi interaksi yang terjadi dapat mengubah manusia yang awalnya tidak mengerti menjadi mengerti, mempengaruhi kehidupan kedepannya, dan dapat memaknai simbol dengan baik. Blumer (dalam Nurhadi.2015:43-46) menyatakan 
bahwa "interaksi manusia dijembatani oleh penggunaan simbol-simbol, oleh penafsiran makna dari tindakan orang lain. Bahasa atau komunikasi melalui simbolsimbol adalah merupakan isyarat yang mempunyai arti khusus yang muncul terhadap individu lain yang memiliki ide yang sama dengan isyarat-isyarat dan simbol-simbol akan terjadi pemikiran (mind)". Dapat disimpulkan bahwa penggunaan bahasa, simbol-simbol, tandatanda, isyarat, dan lain sebagainya adalah metode atau model dalam berkomunikasi dan berinteraksi.

"Teori interaksi simbolik merupakan teori yang mempelajari tentang interaksi antar individu manusia melalui pernyataan simbol, sebab esensi interaksi simbolik terletak pada komunikasi melalui simbol-simbol yang bermakna" (Kusumastuti, 2006:2). Interaksi mendukung komunikasi dapat berupa gerak anggota tubuh, ekspresi wajah, intonasi berbicara, dan lain sebagainya yang kemudian dapat tertangkap secara simbolik maksud dan tujuan interaksi tersebut.

Rumusan masalah dalam penelitian ini adalah bagaimana bentuk pertunjukan Kesenian Sintren Desa Luwijawa Kecamatan Jatinegara Kabupaten Tegal dan bagaimana proses interaksi yang terjadi dalam pertunjukan Kesenian Sintren Desa Luwijawa Kecamatan Jatinegara Kabupaten Tegal. Tujuan dalam penelitian ini adalah untuk mengetahui bentuk pertunjukan Kesenian Sintren Desa Luwijawa Kecamatan Jatinegara Kabupaten Tegal dan mengetahui proses interaksi simbolik yang terjadi pada pertunjukan Kesenian Sintren Desa Luwijawa Kecamatan Jatinegara Kabupaten Tegal.

\section{METODE}

Penelitian ini menggunakan metode kualitatif dengan pendekatan etik dan emik. Teknik pengumpulan data dengan observasi, wawancara, dan dokumentasi. Teknik keabsahan data menggunakan triangulasi sumber, triagulasi teknik, dan triangulasi waktu. Teknik analisis data menggunakan menggunakan Teori Adshead yaitu deskripsi dan interpretasi.

\section{HASIL DAN PEMBAHASAN}

\section{Bentuk Pertunjukan}

Bentuk pertunjukan tari adalah studi tentang bagian-bagian yang ada dalam pertunjukan meliputi tema, pelaku pertunjukan, rias dan busana, gerak, musik iringan, tata cahaya dan suara, tata panggung, dan properti. Interaksi simbolik adalah suatu proses saling memberi, saling mempengaruhi dan bertukar informasi seperti simbol, lambang, atau tanda yang memiliki makna dan hanya dimengerti oleh orang yang berinteraksi.

Keberadaan Kesenian Sintren di Kabupaten Tegal memang sudah terkikis seiring dengan berkembangnya jaman. Sangat jarang ditemui adanya pertunjukan Kesenian Sintren yang di gelar di wilayah Kabupaten Tegal dan beberapa warga yang kurang tau dan kurang mengerti dengan adanya pertunjukan Kesenian Sintren. Selain karena tidak ada generasi penerus kesenian tersebut, masyarakat juga tidak terlalu percaya dengan hal-hal mistis yang terdapat dalam pertunjukan Kesenian Sintren tersebut. Kini Kesenian Sintren di Kabupaten Tegal dihidupkan kembali dan dieksistensikan oleh sekelompok masyarakat yang tergabung dalam Grup Sintren KSYR (Katri Sutri Yubi Raimah) Lestari yang diketuai oleh Mbah Katri, berasal dari Desa Luwijawa Kecamatan Jatinegara Kabupaten Tegal. Tidak hanya sebagai hiburan masyarakat Desa Luwijawa, Kesenian Sintren juga sebagai salah satu mata pencaharian bagi para pelaku pertunjukan kesenian

Suatu pertunjukan kesenian sangat penting adanya elemen-elemen yang mendukung. Jazuli (2016:60) mengemukakan elemen-elemen pertunjukan meliputi tema pertunjukan, penari/pelaku pertunjukan, kostum yang digunakan, musik yang mengiringi, properti yang mendukung keindahan sajian, gerak tari dalam pertunjukan, rias wajah untuk memperkuat karakter, tempat pertunjukan, tata cahaya yang mendukung. Berikut beberapa elemen pertunjukan yang mendukung pertunjukan Kesenian Sintren Desa Luwijawa 
Kecamatan Jatinegara Kabupaten Tegal dikaji menggunakan pendapat Jazuli (2016:60) dijelaskan sebagai berikut; Tema, menurut Murgiyanto (2002:37) mengemukakan bahwa "tema suatu tari dapat berasal dari apa yang kita lihat, kita dengar, kita pikir, dan kita rasakan". Kesenian Sintren Desa Luwijawa Kecamatan Jatinegara Kabupaten Tegal memiliki tema yang berlandaskan pada cerita rakyat karena asal-usul kesenian tersebut bersumber dari cerita rakyat yang berkembang di masyarakat. Pelaku, pertunjukan Kesenian Sintren yang tergabung dalam Grup KSYR Lestari di Desa Luwijawa Kecamatan Jatinegara Kabupaten Tegal memiliki empat kelompok pelaku yaitu mblandang atau pawang bertugas mengatur jalannya pertunjukan, penari yaitu penari Sintren dan penari Badut, pemusik, dan anggota pembantu grup yang bertugas membantu kelancaran jalannya pertunjukan.

Kostum yang akan dikenakan penari Sintren disiapkan pada wadah nampan yang dibungkus kain berwarna biru dan tidak boleh dilihat oleh sembarang orang kecuali mblandang. Sedangkan kostum yang akan dikenakan penari Badut ditempatkan pada wadah besar, semua kostum dan aksesoris untuk penari Badut sudah berada didalam wadah tersebut. penari Sintren dengan menggunakan kostum berupa singlet atau kaos tanpa lengan berwarna merah, kain jarik lurik berwarna putih, stagen hitam, selendang berwarna emas yang dililitkan di pinggang, kaos kaki cokelat, selendang warna jingga yang dikalungkan di leher, sapu tangan warna jingga yang terikat di jari telunjuk tangan kanan penari sintren, tiga buah kalung dengan berbagai model, dan gelang di kedua tangannya. Untuk hiasan kepala penari sintren tidak menggunakan sanggul hanya rambut yang digulung dan diikat menggunakan ikat rambut, mahkota yang menempel di kening, bunga kamboja yang dironce di kedua sisi kepala,bunga melati imitasi, dan kacamata hitam yang menjadi ciri khas penari Sintren. Lebih jelasnya perhatikan foto 1 berikut.

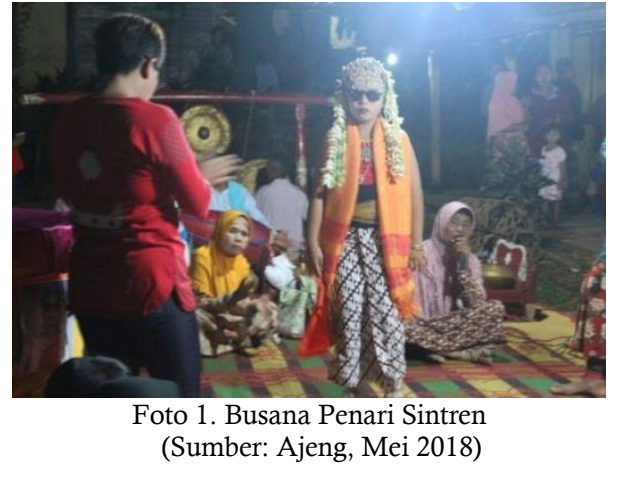

Rias atau make-up yang digunakan oleh penari Sintren dan penari Badut merupakan rias untuk memperkuat karakter yang dibawakan. Penari Sintren menggunakan rias sederana cukup dengan memakai bedak, pensil alis, dan lipstik merah. Penari Sintren tidak melakukan rias sendiri melainkan dirias oleh bidadari dalam kurungan. Berbeda dengan Penasi Sintren yang dirias oleh bidadari, Penari Badut melakukan riasnya sendiri dalam keadaan tidak sadarkan diri.

Menurut Djelantik

(1999:27) mengemukakan bahwa "gerak merupakan terjadinya perubahan tempat, perubahan posisi benda, tubuh penari atau sebagian dari tubuh". Gerak dalam pertunjukan kesenian Sintren, penari Sintren dan penari Badut mengalami kerasukan. Gerak yang ditarikan penari Sintren sangat sederhana dengan mengandalkan gerakan kecil dan sempit pada kaki dan tangan. Gerakan tangan banyak menggunakan gerakan lembehan tangan bawah sambil memegang selendang, sedangkan gerak kaki hanya gejug kanan kemudian gejug kiri dilakukan bergantian dan terus menerus. Begitu pula dengan penari Badut yang menari dengan gerakan sederhana yang mengandalkan gerakan sempit dari tangan dan kaki. Penari Badut sebenarnya menari untuk mendampingi penari Sintren, oleh karena itu kemanapun dan dimanapun penari Sintren menari tentu penari Badut akan mengikuti. Kedua kaki digerakan bergantian. Kaki kanan gejug jinjit dan kaki kiri menapak. Kaki kiri gejug jinjit dan kaki kanan menapak. Pinggul digerakan ke kanan dan ke kiri mengikuti gerakan gejug kaki. Gerakan kedua tangan tidak 
sama. Tangan kanan ke depan dada, kemudian turun ke samping. Tangan kiri tetap di samping memegang sampur sesekali sampur tersebut diseblak.

Terdapat bagian pertunjukan kembang mawar, yaitu mblandang memberikan wadah baskom untuk dipegang penari Sintren dan penari Badut sebagai tempat uang dari penonton. Mblandang memakaikan sandal pada penari Sintren dan penari Badut kemudian menuntun berjalan ke arah kerumunan penonton.

Setelah selesai penari Sintren dan penari Badut kembali memasuki arena pertunjukan dan kembali menari bersama. Bagian saweran, penari Sintren akan menghampiri penonton yang menyawer atau penonton yang menghampiri penari Sintren untuk memberikan uang, Penari Sintren akan mencium tangan atau pipi orang yang memberikan saweran sebagai wujud terimakasih. Penari Sintren akan mengkalungkan selendangnya ke penonton untuk menari bersama, tidak jarang penari Sintren menari tetap menggunakan gerakan inti untuk menari bersama penonton. Penari Sintren dan penari Badut yang sedang menari bersama dan melakukan beberapa interaksi yang menarik dan tidak terduga. Lebih jelasnya perhatikan gambar 2 berikut:

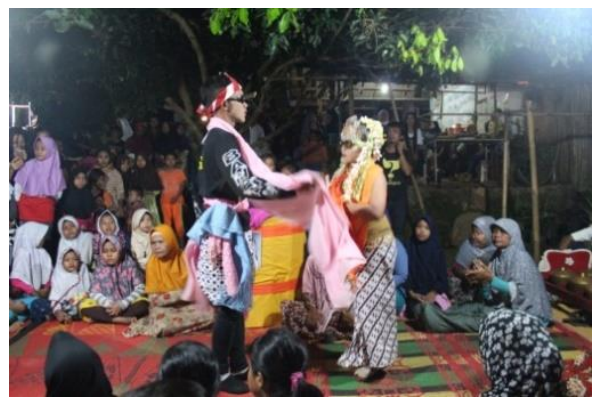

Foto 2. Penari Sintren Dan Badut Menari Bersama (Sumber: Wawan, Mei 2018)

Pertunjukan Kesenian Sintren Desa Luwijawa, menggunakan musik gamelan dan syair aji-aji sebagai pengiring jalannya pertunjukan Kesenian Sintren. "Musik sebagai pengiring tari dapat dianalisis fungsinya sebagai iringan ritmis gerak tarinya, dan berfungsi sebagai ilustrasi pendukung suasana tema tariannya, atau dapat terjadi kedua fungsinya secara harmonis" (Hadi,
2011:28). Syair aji-aji sintren dinyanyikan oleh mblandang yang juga sebagai pawang dan pengatur jalannya pertunjukan. Syair aji-aji yang dinyanyikan bukanlah syair ajiaji biasa melainkan memiliki makna dan maksud tertentu. Semua sair aji-aji dinyanyikan berurutan sesuai fungsinya, tidak jarang penari Sintren memilih sendiri syair aji-aji apa yang akan dinyanyikan. Apabila syair tersebut tidak sesuai dengan keinginan atau kurang enak didengar, Penari Sintren akan melakukan protes kepada pemusik atau tidak akan menari dan hanya duduk bersimpuh saja.

Kesenian sintren Desa Luwijawa Kecamatan Jatinegara Kabupaten Tegal termasuk kesenian kerakyatan yang dapat pentas dimana saja. Di arena terbuka yang mempunyai banyak ruang atau luas seperti lapangan, halaman rumah warga, dan lainnya sehingga penonton dapat menyaksikan pertunjukan dari segala sisi. Tidak ada panggung dalam pertunjukan, cukup menggunakan tikar, karpet, atau terpal sebagai alas duduk para pelaku pertunjukan untuk pentas.

Pertunjukan Kesenian Sintren cukup dengan menggunakan dua buah lampu LED yang dipasang menggantung menggunakan tali di atas tempat pertunjukan yang aliran listriknya didapat menyambung dari rumah warga, selain itu juga dibantu oleh penerangan dari lampu teras rumah warga sekitar. Pencahayaan yang sangat minim tersebut menambah kesan mistis dalam pertunjukan Kesenian Sintren. Pada pertunjukan Kesenian Sintren Desa Luwijawa menggunakan beberapa properti yang sederhana, yaitu satu kurungan Sintren, tungku arang, kemenyan dan sesaji, dan alat make-up.

\section{Interaksi Simbolik}

Penelitian ini mengkaji mengenai interaksi simbolik menurut teori Blumer. Blumer menerangkan interaksi simbolik dapat dilihat melalui tiga tahap yaitu pikiran (thought), bahasa (language), dan pemaknaan (meaning). Pikiran, pada hakekatnya bersumber pada apa yang diyakini sehingga hal-hal yang dipikirkan dan terjadi sesuai dengan apa yang diyakini. Bahasa, dari bahasa memperoleh banyak makna. Bahasa dapat dilakukan 
secara verbal dan non verbal. Pemaknaan, sebagai sebuah proses dengan diri sendiri, dimana pikiran akan mengolah informasiinformasi atau simbol-simbol yang diterima. Proses interaksi simbolik terjadi pada tiga waktu yaitu sebelum pertunjukan, saat pertunjukan berlangsung, dan sesudah pertunjukan. Interaksi sebelum pertunjukan antara lain : 1) pemain dengan pemain yang melibatkan penari sintren dengan mblandang terjadi ketika penari sintren diajak masuk ke kamar untuk ritual "diisi" oleh mblandang, penari badut dengan mblandang terjadi ketika mblandang membantu penari badut memakai kostum dan aksesoris; 2) pemain dengan pemusik terjadi ketika pemusik melirik dan tersenyum ke arah mblandang dan penari sintren ketika memasuki arena pertunjukan; 3) penonton dengan penonton terjadi ketika penonton saling bertegur sapa saat tiba di arena pertunjukan; 4) pemusik dengan pemusik terjadi ketika salah satu alat untuk nabuh gamelan tidak ditemukan, dalam hal ini terdapat interaksi verbal; 5) penonton dengan pemusik terjadi ketika pemusik mulai memainkan alat musik sebagai pertanda pertunjukan segera dimulai dan sebagai ajakan untuk warga agar menonton pertunjukan kesenian Sintren. Interaksi saat pertunjukan berlangsung terjadi pada saat pemain dengan pemain yang melibatkan penari Sintren dengan mblandang terjadi ketika mblandang membacakan doa dan meniup kening penari sintren kemudian kedua tangan penari Sintren diikat, hal tersebut dimaknai sebagai mblandang sedang membacakan aji-aji agar penari Sintren diberikan kelancaran dan keselamatan dalam pertunjukan. Ketika mblandang membuka dan menutup kurungan penari sintren, ketika mblandng mengarahkan penari sintren kemana harus berjalan dan menghadap dengan digandeng tangannya, ketika mblandang mencoba berkomunikasi secara verbal dengan penari Sintren, serta banyak lagi interaksi yang terjadi. Sebagai contoh ketika Mbah Katri sedang berinteraksi dengan penari Sintren yang ada dalam kurungan dengan cara menempelkan telinga ke sisi urungan dan mendengarkan kata yang dicupakna penari
Sintren, hal tersebut dimaknai dengan sebuah cara mblandang untuk mengetahui kesiapan penari Sintren. Lebih jelasnya lihat foto 3 berikut,

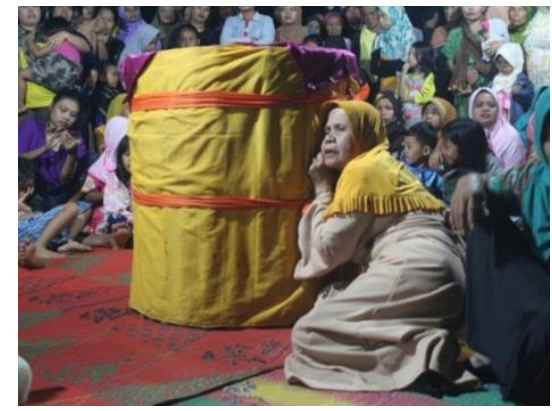

Foto 3. Mbah Katri Berinteraksi dengan Penari Sintren

(Sumber: Ajeng, Juni 2018)

Berikut interaksi verbal yang terjadi,

\section{Ibu Sutri: "Pimen? Wis gelem?"} (Bagaimana? Sudah mau?)

Mbah Katri: "Ora, durung gelem. Njaluke blenderan maning koh kesel nembange" sambil menggelengkan kepala.

(belum mau. Minta dinyanyikan syair Solasih-Solandono lagi, capek nyanyinya)

Ibu Sutri: "Yawis meneh nyong maning sing nembang ben gelem metu"

Sambil mengambil mikrofon. (yaudah sini aku lagi yang nyanyi biar mau keluar)

Mblandang dengan mblandang terjadi ketika mblandang bersama-sama mulai menyanyikan syair mantra, ketika mblandang mendapat isyarat dari penari Sintren dan langsung diteruskan kepada mblandang lain, serta banyak interaksi lain yang terjadi. Penari badut dengan mblandang terjadi ketika penari badut sudah di arena pertujukan, ketika penari badut mendapat kipatan sapu tangan dari penari Sintren, ketika mblandang menenangkan penari Badut yang dalam keadaan kerasukan, serta beberapa interaksi lain yang terjadi secara tidak terduga.

Berikutnya adalah interaksi pemain dengan penonton terjadi ketika adegan kembang mawar yaitu penari sintren dan penari badut didampingi 
mblandang menuju kerumunan penonton sambil membawa baskom untuk tempat penonton memberikan uang, kemudian interaksi terjadi ketika penonton memasuki arena pertunjukan untuk memberikan saweran dan menari bersama penari Sintren dan penari Badut, lebih jelasnya lihat foto 4 berikut,

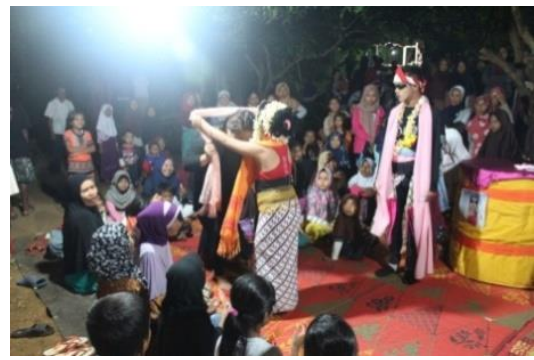

Foto 4. Penari Sintren Mengalungkan Selendang kepada Penonton

(Sumber: Ajeng, Mei 2018)

Interaksi selanjutnya adalah antara pemain dengan pemusik terjadi ketika penari Sintren memberikan tanda kapan musik berhenti dan berganti untuk kemudian diteruskan oleh mblandang kepada pemusik, ketika penari Sintren menunjukan gerak tubuh seperti marah sebagai tanda protes karena menganggap iringan yang dimainkan kurang sesuai dengan keinginannya.

Interaksi penonton dengan penonton terjadi ketika sesama penonton saling memberikan tanggapan dan komentarnya mengenai pertunjukan kesenian Sintren. Interaksi berikutnya terjadi antara pemusik dengan pemusik, ketika salah satu pemusik memberi tahu kepada pemusik lain mengenai iringan mana atau notasi apa yang harus dimainkan. Kemudian interaksi pemusik dengan penonton terjadi ketika banyak penonton yang ikut menyanyikan syair mantra bersama dengan mblandang dan iringan musik.

Interaksi sesudah pertunjukan terjadi pada: 1) Pemain dengan pemain terjadi ketika mblandang dibantu anggota pembantu grup mengakhiri pertunjukan dan menyadarkan kembali penari sintren dan penari badut dari kerasukan; 2) Pemain dengan penonton terjadi ketika beberapa penonton memilih tetap tinggal dan mengobrol dengan para pemain kelompok kesenian Sintren; 3) Pemain dengan pemusik terjadi ketika mblandang dan pemusik memandikan penari Sintren dan penari Badut menggunakan air kembang, lebih jelasnya perhatikan foto 5 berikut,

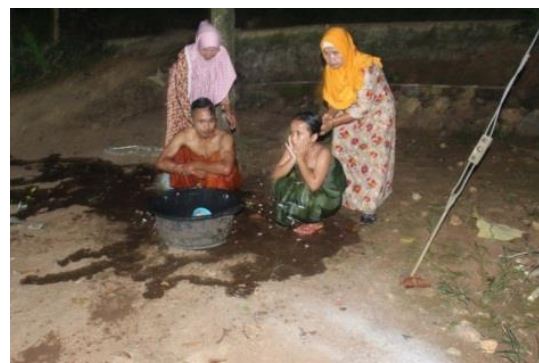

Foto 5. Penari Sintren dan Penari Badut Mandi Air Kembang

(Dokumentasi: Ajeng, Mei 2018)

\section{SIMPULAN}

Interaksi simbolik yang terjadi pada sebuah pertunjukan menjadi sebuah bentuk baru baik secara verbal maupun non verbal dan terealisasikan dalam katakata atau simbol. Proses interaksi simbolik pertunjukan Kesenian Sintren terjadi pada tiga waktu, yaitu sebelum pertunjukan, saat pertunjukan berlangsung dan sesudah pertunjukan. Proses interaksi sibolik terjadi pada pemain dengan pemain, pemain dengan pemusik, pemain dengan penonton, pemusik dengan pemusik, penonton dengan penonton.

Beberapa hal dalam pertunjukan perlu lebih diperhatikan, seperti kostum penari Sintren dan Penari badut yang cenderung sederhana mungkin dapat ditambahkan beberapa aksesoris agar lebih menarik, pencahayaan yang memadai, tempat pertunjukan yang perlu inovasi baru agar lebih indah. Bila perlu pemusik dan mblandang serta anggota pembantu grup memakai pakaian yang seragam agar terlihat lebih kompak dan manis. Perlu diperhatikan pula proses regenerasi para pelaku pertunjukan mengingat Mblandang dan pemusik yang sudah berusia lanjut agar Kesenian Sintren Desa Luwijawa Kecamatan Jatinegara Kabupaten Tegal terus terjaga kelestariannya dan semakin berkembang. 


\section{DAFTAR PUSTAKA}

Djelantik, A.A. 1999. Estetika Sebuah Pengantar. Bandung: masyarakat Seni Pertunjukan Indonesia

Jazuli. 2001. Metode-Metode Kualitatif. Semarang: Universitas Negeri Semarang.

. 2016. Peta Dunia Seni Tari. Semarang: Farisfma Indonesia

Kusumastuti, Eny. 2006. "Laesan Sebuah Fenomena Kesenian Pesisir: Kajian Interaksi Simbolik Antara Pemain Dan Penonton". Harmonia Jurnal Pengetahuan dan Pendidikan Seni. Vol. VII. Nomor 3. Halaman 2. Semarang: Universitas Negeri Semarang.

Murgiyanto, Sal. 2002. Kritik Tari Bekal dan Kemampuan Dasar. Jakarta: Msyarakat Seni Pertunjukan.

Nurhadi, Zikri Fachrul. 2015. Teori-Teori Komunikasi. Bogor: Ghalia Indonesia.

Sugiyono. 2016. Metode Penelitian Pendidikan Pendekatan Kuantitatif, Kualitatif, dan R\&D. Bandung: Alfabeta.

Sumandinyo, Hadi. 2011. Koreografi (Bentuk-Teknik-Isi). Yogyakarta: Multi Grafindo 